\title{
Making the Case for Equity Pedagogy
}

\section{Margaret Thomas}

I have spent most of my career teaching music theory at a small liberal arts college where all students enter without a major. They're encouraged to explore a range of disciplines before declaring a major; ostensibly, all fields are available to them. Too often, however, interested students encounter barriers to entering the music major. They may find that their background doesn't match the expectations of the music department, or they may find that their particular musical interests are not represented in our course offerings. In recent years these kinds of issues have driven curricular redesign at a number of institutions. ${ }^{1}$ When discussing the motivation for recent changes to the music major at Harvard University, for example, Anne Shreffler noted that "our old curriculum was saying to those students: 'You cannot major in music because your parents did not give you 12 years of this kind of education that we implicitly require"' (Robin 2017).

The implicit requirements that Shreffler alludes to, requirements common to most undergraduate music majors, are complex and messy. The expectation of prior training in the Western Classical tradition is inextricably linked with factors of race, class, and cultural background. Initiatives to decolonize and diversify our field, to recognize discrimination and injustices in it, and to improve the pipeline to music academia are generating important discussions. The discipline of music seems to be undergoing a kind of reckoning, of which widespread curricular redesign is one indicator.

Yet undertaking substantive curricular reform at the institutional level is challenging and time-consuming, and it alone is not enough: changes to the curriculum must be paired with changes in pedagogy. Here I explore impactful steps that individual instructors can take to address issues of inequity in their own teaching, steps that not only complement broader institutional curricular undertakings but are critical to such undertakings. I don't offer solutions so much as I offer questions, the first and perhaps most important of which is: how do we know what is keeping students away if we don't have access to their stories?

I was fortunate to serve as a faculty mentor for the Posse Foundation's Scholars program from 2016 to 2020, working intensively with eleven students ("Posse Scholars") from Chicago from the summer prior to their arrival at my 


\section{Project Spectrum Colloquy}

college through their graduation. ${ }^{2}$ I knew that this mentoring would be hard work, and that I would learn a lot. What I didn't expect is that it would give me a radically new perspective on the student experience both at the college and in our music department. The Scholars arrived with a wide range of academic interests. Three wanted to become involved in music. One had a background as a saxophonist and had come from a public school with a pretty strong music program. One simply wanted to take a few music courses and sing in choir. And one was interested in majoring: she was passionate about music, even though she had never formally studied it. As it turned out, none of these three Scholars persisted in our music department beyond one or two semesters. Having intimate access to their experiences as their mentor woke me up, broke my heart, and inspired me to try to do even more to craft courses and classrooms that foster the full participation of all learners. One Scholar's experience in a theory fundamentals course exposed and personalized the inaccurate and biased assumptions we tend to make of students in music courses, assumptions that exemplify the implicit requirements for becoming a music major. Let's call the Scholar "K.M." Throughout the semester, K.M. and I frequently discussed how difficult she found the theory course to be. It was only after she had completed it that I got a fuller sense of her experience. She said:

As soon as I walked in and saw all those white kids, I knew it was going to be rough. The teacher asked about our musical background, and it seemed like everyone except me had played an instrument before, and already knew how to read music. The class moved so fast! I think those other kids were able to keep up in a way I couldn't. The teacher just told me to work harder.

- "K.M.," a Posse Scholar

A number of salient points in this quotation are likely obvious to the reader, and may feel familiar. My institution is predominantly white, and the music department is more so. Although this class is advertised as being geared to students with no musical training, it appears that it is not, in fact, designed for students with no experience. Once the class was underway, some students were clearly left behind. The course instructor did not comprehend the Scholar's experience, an experience that was no doubt shared by other students.

How can we, as individual faculty members, confront the possibility that this may be happening in our own teaching without our awareness of it? What steps can we take as we design and deliver our courses to minimize the likelihood that we will create a situation like the one I describe, only discovering too late that we did not meet the needs of all of our students, that we did not create a 


\section{Current Musicology}

learning environment that supports all learners? I propose drawing on two educational theories: universal design for learning (UDL) and equity pedagogy.

UDL is an educational framework that's likely familiar to many faculty members. It is derived from the universal design movement in architecture and urban planning of the 1980s that advocated for proactive design that benefits the greatest range of physical abilities as possible, thereby reducing the need for individual accommodations and retrofitting existing structures. Similarly, the principle of UDL argues for proactive course design that plans for student learning variability by providing what the Center for Applied Special Technology (CAST) describes as "multiple means of engagement, representation, and action/expression" (2020). Bruce Quaglia presents a rich and detailed application of UDL specific to the music theory classroom, arguing: "Only by clearly distinguishing between our intended learning objectives and the methods that we use to achieve them can we determine when an unnecessary barrier to learning has inadvertently entered into our curriculum" (2015, [3.1]).

As with UDL, the principle of equity pedagogy encourages a close examination of course design, paying attention not only to content, but to delivery and assessment. As a framework, it is likely less familiar than UDL, but it has been fundamental to educational discourse since the 1990s (Banks and Banks 1995). The concept of equity pedagogy aligns so productively with the current movement to address biases and structural racism in music higher education-a movement exemplified by Project Spectrum - that (as I state in my title) I want to make a case for bringing it into our work as music pedagogues. Equity pedagogy requires teachers to be vulnerable and to take a hard look at what we do, at how we behave, and at our own biases in order to work toward achieving "equity literacy." Its point of reference is inequity. Paul Gorski, a leading figure in equity pedagogy, notes that much curricular reform has been based on the "indefensible premise that we can achieve equity by ignoring inequity" (2016, 222). He adds that "no amount of cultural knowledge can prepare us sufficiently to recognize and respond justly to the insidious and often implicit and intersectional inequities experienced by many students-to the racism, xenophobia, heterosexism, ableism, economic injustice, Islamophobia, sexism, and other oppressions they may experience through unjust educational policy and practice" $(2016,224)$.

While Gorski's work largely focuses on K-12 education, I firmly believe that the framework of equity pedagogy has much broader applicability. Gorski challenges us to develop our own equity literacy in order to "be a threat to inequity in our spheres of influence" (2018). How do we do that? We have to ask 


\section{Project Spectrum Colloquy}

ourselves some tough questions. We have to do a great deal of honest selfreflection. A starting point that can be very revealing is to examine our courses as objectively as possible for the ways in which they enact what Gorski describes as four different curricula: (1) the official curriculum (the syllabus, assignment descriptions, exams, and so on); (2) the explicit curriculum (the content that is purposefully taught); (3) the hidden or implicit curriculum (the values and ideas that are taught implicitly); and (4) the null curriculum (the values and ideas that are taught by what is omitted from the explicit curriculum) (2018). An exercise like this can help us to begin the hard work of recognizing inequities that we may perpetuate in our own teaching. This process of recognition is the first step toward developing "equity literacy." Once we recognize inequity, Gorski then challenges us to respond to inequity in both the immediate and in the long terms, and to commit to sustaining equity, "even in the face of resistance" $(2016,225)$.

As our gaze shifts from scrutiny of particular courses outward, I would argue that we will need to consider how the dynamics of privilege and power have operated in our field-how they have affected us personally, and to what extent our curriculum and pedagogy recreate those dynamics. We will need to consider what assumptions we are making about our undergraduate students as they enter our majors. What and whom do we gain and lose by making those assumptions? If we want to understand and dismantle barriers to undergraduate music study, thereby broadening the pipeline to academia, these considerations are critical. The principles of UDL and equity pedagogy can provide a useful framework for undertaking this work. They will help us answer Kevin Gannon's 2018 call to action to develop methods of inclusive teaching, which demands "a realization that traditional pedagogical methods - traditionally applied - have not served all of our students well. It's a commitment to put actual substance behind our cheerful declarations that all students deserve access to higher education." Breaking down the barriers that keep students like K.M. from entering the pipeline will be good for all of us. Let's get to work.

Notes

${ }^{1}$ See, for example, Robin 2017 for a discussion of Harvard's new curriculum, Hovis 2016 for a discussion of Cornell's new curriculum, and Tufts University Department of Music (n.d.) for a description of Tufts's new major in Music, Sound, and Culture, which is "open to undergraduates with any and all prior backgrounds in music."

${ }^{2}$ As described on possefoundation.org, "Posse started in 1989 because of one student who said, 'I never would have dropped out of college if I had my posse with me.' The Posse Foundation identifies public high school students with extraordinary academic and leadership potential 


\section{Current Musicology}

who may be overlooked by traditional college selection processes. The Foundation extends to these students the opportunity to pursue personal and academic excellence by placing them in supportive, multicultural teams-Posses—of 10 students."

\section{References}

Banks, Cherry A. McGee and James A. Banks. 1995. "Equity Pedagogy: An Essential Component of Multicultural Education." Theory Into Practice 34 (3): 152-58.

Bradley, Deborah. 2015. "Hidden in Plain Sight: Race and Racism in Music Education." In The Oxford Handbook of Social Justice in Music Education, edited by Cathy Benedict, Patrick Schmidt, Gary Spruce, and Paul Woodford, 190-203. Oxford: Oxford University Press.

Center for Applied Special Technology. 2020. "The UDL Guidelines.” http://udlguidelines.cast.org/. Accessed October 19, 2020.

DeLorenzo, Lisa C. 2016. "Is There a Color Line in Music Education?” In Giving Voice to Democracy in Music Education: Diversity and Social Justice, edited by Lisa C. DeLorenzo, 176-194. New York: Routledge.

Gannon, Kevin. 2018. “The Case for Inclusive Teaching." The Chronicle for Higher Education. February 27, 2018. https://www.chronicle.com/article/The-Case-for-Inclusive/242636. Accessed March 5, 2018.

Gorski, Paul. 2016. "Rethinking the Role of 'Culture' in Educational Equity: From Cultural Competence to Equity Literacy." Multicultural Perspectives 18 (4): 221-226. . 2018. "Strengthening Equity in Your Teaching \& Course Design." Presentation at Connecticut College. January 17, 2018.

Hovis, Kathy. 2016. "Music Curriculum Expands to Reach Students of Diverse Musical Backgrounds." https://as.cornell.edu/news/playing-new-tune-revamped-musiccurriculum-reaches-students-diverse-musical-backgrounds. Accessed March 11, 2018.

Koza, Julia Eklund. 2009. "Listening for Whiteness: Hearing Racial Politics in Undergraduate School Music." In Music Education for Changing Times: Guiding Visions for Practice, edited by Thomas A. Regelski \& J. Terry Gates, 85-95. New York: Springer.

Madrid, Alejandro L. 2017. "Diversity, Tokenism, Non-Canonical Musics, and the Crisis of the Humanities in U.S. Academia." Journal of Music History Pedagogy 7 (2): 124-130.

Quaglia, Bruce W. 2015. "Planning for Student Variability: Universal Design for Learning in the Music Theory Classroom and Curriculum." Music Theory Online 21 (1). https://doi.org/10.30535/mto.21.1.6

Robin, William. 2017. "What Controversial Changes at Harvard Mean for Music in the University." National Sawdust Log. April 27, 2017.

https://nationalsawdust.org/thelog/2017/04/25/what-controversial-changes-atharvard-means-for-music-in-the-university/. Accessed May 5, 2017.

Sarath, Edward W., David E. Meyers, and Patricia Shehan Campbell. 2016. Redefining Music Studies in an Age of Change: Creativity, Diversity, and Integration. New York: Taylor and Francis. 


\section{Project Spectrum Colloquy}

Smith, Gareth Dylan. 2016. "Neoliberalism and Symbolic Violence in Higher Music

Education." In Giving Voice to Democracy in Music Education: Diversity and Social Justice, edited by Lisa C. DeLorenzo, 65-84. New York: Routledge.

Tufts University Department of Music. N.d. "Undergraduate Studies."

https://as.tufts.edu/music/students/undergraduate/majorMusic2. Accessed January 5, 2021. 